\title{
DIFERENCIAÇÃO ESPACIAL COMO ELEMENTO PRÓPRIO À NATUREZA DA GEOGRAFIA
}

\author{
Prof $^{\mathrm{a}}$. Dra ${ }^{\mathrm{a}}$. Kelly Bessa \\ Programa de Pós-Graduação em Geografia da UFT, campus de Porto Nacional \\ Programa de Pós-Graduação em Ciências do Ambiente da UFT, campus de Palmas \\ Rua 07, Quadra 15, s/n - Jardim dos Ipês, CEP: 77500-000 - Porto Nacional (TO) Brasil \\ Tel./Fax: (+ 55 63) 33630504 / 33630501 - kellybessa@uft.edu.br
}

\begin{abstract}
RESUMO
A diferenciação espacial consiste, aparentemente, em um conceito banal e de fácil compreensão, já que a diferença sobressai no plano do imediato e do diretamente perceptível. Porém, essa banalidade desmistifica-se quando se considera a possibilidade de ser a diferenciação espacial um elemento essencial à natureza da Geografia, porque mais do que consciência ou reconhecimento trivial da existência da diferenciação espacial em sua reflexividade prático-empírica, é preciso concebê-la em sua reflexividade teórico-metodológica. Possibilitar a diferenciação espacial como uma materialidade e como uma categoria analítica representa o desafio deste texto.
\end{abstract}

Palavras-chaves: Diferenciação espacial, natureza da Geografia, categoria analítica.

\begin{abstract}
The spatial differentiation is, apparently, an unimportant concept and easy understand, because the difference stands out in the plan immediate and directly perceptible. But, the unimportantly of this concept is watched when is considered the possibility to be the spatial differentiation an essential element of the nature of Geography, because more than conscience or recognition trivial of the existence of the spatial differentiation in your reflection practical-empirical, is necessary to conceive it in your reflection theoretical-methodological. To turn possible the spatial differentiation as a concrete reality and as a analytical category it represents the challenge of this text.
\end{abstract}

Key words: Space differentiation, nature of the Geography, analytic category.

\section{RESUMEN}

La diferenciación espacial consiste, aparentemente, en un concepto común, de fácil comprensión, ya que la diferencia sobresale en el plan del inmediato y del directamente perceptible. Sin embargo, esta trivialidad se desmitifica cuando se considera la posibilidad de que la diferenciación espacial sea un elemento esencial a la naturaleza de la Geografía, porque más que conciencia o reconocimiento trivial de la existencia de la diferenciación espacial en su reflexividad práctico-empírica, hay que concebir en su reflexividad teórica- metodológica. Posibilitar la diferenciación espacial como una materialidad concreta y como una categoría analítica es el desafío de este texto.

Palabras-clave: Diferenciación espacial, naturaleza de la Geografía, categoría analítica.

\section{INTRODUÇÃOO}

Em diversos momentos, e sob posturas epistemológicas e metodológicas distintas, a diferenciação espacial surge na análise geográfica, como, por exemplo, no artigo de Santos (1999, p.5-6), Modo de Produção Técnico-Científico e Diferenciação Espacial, em que o autor ressalta que "[...] a palavra 'espaço', da qual a expressão 'diferenciação espacial' é uma decorrência, tem sido utilizada com a maior imprecisão no vocabulário da Geografia". Vale acrescentar que, por extensão, tal imprecisão estende-se também à própria noção de diferenciação espacial. Moreira (1999, p.46), por sua vez, assinala que "[...] diferença na Geografia é diferenciação" ou, ainda, que "[...] diferenciação e heterogeneidade são os termos da diferença na Geografia", sendo possível incluir ambos na noção de diferenciação espacial, pois, como afirma o referido autor, “[...] a categoria heterogeneidade não atua entretanto sozinha [...], ao seu lado intervém a categoria da diferenciação". Corrêa (1995, p.35), examinando espaço como um conceito-chave da Geografia, preceitua que "[...] as práticas espaciais resultam, de um lado, da consciência que o homem tem da diferenciação espacial [...]" e "[...] de outro lado são ingredientes através dos quais a diferenciação espacial é valorizada". No livro Região e Organização Espacial, Corrêa (1991, p.8) argumenta ainda que a natureza da Geografia “[...] tem suas raízes na busca e no entendimento da diferenciação de lugares, regiões, países e continentes, 
resultante das relações entre os homens e entre estes e a natureza". Gregory (1989), por sua vez, vem introduzindo a discussão da diferenciação de área nos debates acerca da Geografia Humana pós-moderna. Massey (1984) também dedica especial interesse pela diferenciação espacial, particularmente, no que se refere à preocupação com os mecanismos geradores do desenvolvimento desigual do espaço. Ressalta-se que Massey (1981, p.52) busca reabilitar a noção de região em paralelo com a de diferenciação espacial, esclarecendo que "[...] o propósito dos trabalhos sobre regionalismo é procurar entender a formação, a natureza e os efeitos da diferenciação espacial". Lacoste (1980), discutindo unidade e diversidade, coloca em destaque a noção de espacialidade diferenciada, a qual seria mais bem denominada de diferenciação espacial.

Esses são apenas alguns exemplos nos quais a diferenciação espacial é discutida como essencial aos estudos geográficos. No entanto vários outros trabalhos poderiam ser citados, visto o largo emprego do termo diferenciação espacial, porém, apesar da rica bibliografia, tal termo aparece de maneira bastante imprecisa e diluída nas pesquisas geográficas.

$\mathrm{Na}$ verdade, trata-se de um termo familiar à Geografia, visto ser esta a ciência do espaço e das categorias espaciais, cujo objetivo é interpretar a espacialidade das realidades sociais, quer dizer, é tornar essas realidades inteligíveis sob seu aspecto espacial, ou ainda, como ensina Haesbaert (2004, p.20), é “[...] elucidar as questões atinentes à dimensão espacial”. A Geografia, de fato, sempre se estruturou no sentido de produzir um conhecimento de natureza espacial: o positivismo clássico orientou a construção de uma geografia das aparências, de uma geografia das superfícies ; a abordagem do positivismo lógico determinou a constituição de uma geografia do padrão espacial; e, na perspectiva do materialismo histórico-dialético, a produção da sociedade ocorre sob a forma de produção do espaço, possibilitando a construção de um saber socioespacial. Todavia tal processo tem como resultante um espaço fragmentado e desigual e, desta maneira, criou-se uma geografia das desigualdades socioespaciais.

O espaço, entretanto, apresenta-se qualitativo e quantitativamente diferenciado. Dificilmente se pode olhar para o mundo sem perceber os distintos conteúdos espaciais, que se assentam sob uma base natural e uma base social. Como argumenta Smith (1988, p.153), “[...] as diferenças qualitativas na natureza se traduzem em diferenças qualitativas e quantitativas na organização social", e são definidas mediante uma contínua reorganização, quer dizer, a vida social caracteriza-se por uma incessante renovação: na prática socioespacial, o mundo revela-se em suas diferenças, ou seja, em suas diversidades, fundamentos primeiros da própria organização socioespacial, aos quais foram acrescentados as contradições e os antagonismos próprios da reprodução desigual das sociedades.

Nessa perspectiva aparente, a diferenciação espacial é um conceito banal e de fácil compreensão, pois a diferença salta aos olhos, sobressai no plano do imediato e do diretamente perceptível, visto ser inerente à natureza e às relações humanas. Dessa maneira, a diferenciação espacial seria, simplesmente, um correspondente geográfico, isto é, a diferença, condição essencial, imanente, expressa no espaço, uma vez que é visível tanto nas condições naturais (solo, vegetação, clima) quanto nos aspectos sociais (economia, política, cultura). Dessa maneira, à medida que ambos, aspectos físicos e sociais, diferenciam-se no espaço, tem-se como resultado a diferenciação espacial, isto é, tem-se uma organização diferenciada do espaço. Na verdade, o espaço exprime, tanto nos objetos como nas práticas socioespaciais, formas de organização das diferenças.

Destarte, nesse imediatismo perceptível do dado aparente dissolve-se o sentido mais amplo da diferenciação espacial como conceito e possibilidade analítica. Contudo essa banalidade desvela-se quando se considera a possibilidade de ser a diferenciação espacial um elemento próprio da natureza da Geografia. Como categoria de entendimento da realidade, a diferenciação espacial tem um significado abrangente e complexo, que envolve uma gama de outros conceitos chave, sob diversas possibilidades epistemológicas e metodológicas. Assim, mais do que consciência ou reconhecimento banal da existência da diferenciação espacial em sua concreticidade, é preciso concebê-la em sua riqueza analítica, para, dessa forma, não permitir que se dissolva, no imediatismo do dado aparente, o seu sentido mais amplo. Possibilitar a diferenciação espacial como uma realidade e uma cate- 
goria analítica representa desafio importante e, nesta perspectiva, inquietações colocam-se como questões para a reflexão: Qual seria a verdadeira dimensão desse termo tão familiar à Geografia? A diferenciação espacial constitui-se de fato em uma das visões a respeito da natureza da Geografia? Se este é o caso, quais os conteúdos presentes na evolução do pensamento geográfico, sobretudo, na interpretação das correntes Teorético-Quantitativa e Crítica?

\section{DIFERENCIAÇÃO ESPACIAL E A PERSPECTIVA DA GEOGRAFIA}

Ao longo de sua história, a Geografia construiu expectativas com relação à interpretação da espacialidade dos fenômenos que se referem à ação humana modelando a superfície terrestre. Anteriormente ao processo de sistematização da disciplina por Humboldt e Ritter, Kant desenvolveu a ideia de que "[...] a Geografia constituir-se-ia na ciência que estudava todos os fenômenos organizados espacialmente" (CORRÊA, 1995, p.18). O espaço, contudo, não representou um conceito-chave para a Geografia Clássica, que privilegiou os conceitos de paisagem e de região. Todavia o espaço está presente, ainda que de maneira implícita, nas obras de Ratzel, que, em sua Antropogeografia, desenvolveu as noções de território e de espaço vital; de Hettner, que fundamentava suas análises no pressuposto de que a Geografia era "[...] a ciência da superfície terrestre segundo suas diferenças regionais" (citado por MENDOZA, et al., 1982, p.73), uma vez que a noção de região estava alicerçada em variações geográficas resultantes de variações naturais; e também de Hartshorne (1939), que, além de introduzir a noção de espaço absoluto, valorizava a idéia de que a Geografia define-se pelo estudo das diferenças regionais. Autores como La Blache, Sauer e Hartshorne enfatizaram a diferenciação de áreas como questão fundamental para a natureza dos estudos geográficos. Não obstante, o conceito de região, tão caro à Geografia Clássica, está "[...] na base da concepção científica da diferenciação espacial", ou melhor, a região é "[...] uma forma de ver o espaço que coloca em evidência os fundamentos da organização diferenciada do espaço", como salienta Gomes (1996, p.240; 1995, p.60).

Entretanto a diferenciação espacial e seus respectivos vínculos com a natureza da Geografia, apesar de já estarem presentes na Geografia Clássica, são mais bem percebidos nas correntes lógico-formal e crítico-radical, pois estas estão diretamente vinculadas à noção de espaço, da qual a diferenciação espacial é decorrência e conteúdo substancial.

A Geografia Teorético-Quantitativa foi responsável, em grande parte, pela introdução de uma visão espacialista, na qual o espaço tornou-se uma variável-chave e a diferenciação espacial, dele decorrente, também passou a representar importante viés de análise . Há que se destacar, entretanto, que a concepção de espaço dos geógrafos teorético-quantitativistas é limitada, como salienta Corrêa (1995), e, por esta razão, a discussão da diferenciação espacial parece pouco apropriada nessa corrente. No entanto, em não se tratando, por um lado, de análises com demasiada ênfase em geometrias estéreis ou em abstrações progressivas, geralmente realizadas segundo posição extremamente formalista e mecanicista daqueles geógrafos fortemente influenciados pela lógica positivista; e, em se considerando, por outro lado, as variações e os mecanismos econômicos utilizados na análise espacial e na elaboração dos padrões espaciais, é possível perceber que a Geografia Teorético-Quantitativa não perdeu de vista a diferenciação espacial como possibilidade de análise. Gregory (1996, p.99) frisa que havia versões “[...] mais adiantadas da análise espacial teorético-quantitativa", que não eram "[...] unicamente determinadas pela contemplação geométrica". Tais versões "[...] focalizavam modelos parciais ou gerais de um panorama econômico... [ou de uma] ...economia do espaço"! .

A análise da organização espacial foi considerada por meio das noções de planície isotrópica e de representação matricial, nas quais se observam as premissas da racionalidade econômica, da competição perfeita e da a-historicidade dos fenômenos, como informa Corrêa (1995). Tais noções e premissas não são mutuamente excludentes, pois são elaborações teóricas que permitem um caráter de generalidade, isto é, possibilitam a construção de modelos teóricos, apoiados no

Mercator - volume 9, número 20, 2010: set./dez. 
raciocínio lógico-matemático, que, na perspectiva racionalista e hipotético-dedutiva, compensa a perda de detalhes ou de especificidades pela generalização. A diferenciação espacial é constatada mediante tais construções teóricas. Para tanto, como declara Corrêa (1995, p.21), “[...] o ponto de partida é a homogeneidade, enquanto o ponto de chegada é a diferenciação espacial que é vista como expressando um equilíbrio espacial", haja vista que "[...] diferenciação e equilíbrio não são, assim, estranhos entre si nesta concepção". O autor observa que, previamente à condição de diferenciação do espaço, se tem, para fins de análise, um espaço homogêneo, a exemplo da planície isotrópica, onde a variável mais significativa é a distância . Corrêa (1995, p.21) assevera que "[...] sobre essa planície de lugares iguais desenvolvem-se ações e mecanismos econômicos que levam à diferenciação do espaço."

Na Figura 1, tem-se um exemplo de operacionalização da matriz matemática e da planície isotrópica. Nele, nota-se que tal representação confere ao espaço um caráter topológico ou matricial, características que não impedem os processos de diferenciação espacial - pois fica evidente a condição inicial de homogeneidade na Figura 1 (7.1), em que os pontos são indiferenciados e não sofrem o efeito da distância; na Figura 1 (7.2), apesar da fricção da distância, os pontos permanecem indiferenciados; na Figura 1 (7.3), por sua vez, com a interferência da distância, verifica-se uma diferenciação entre os pontos; na Figura 1 (7.4), finalmente, estabelece-se um espaço diferenciado, com presença de outras variáveis - a princípio relacionados com o fator distância, a exemplo da permeabilidade e da barreira de absorção. Tais variáveis, certamente, irão ampliar a distinção entre os pontos, assim como a natureza do movimento, alterando por completo a situação de uniformidade em prol da heterogeneidade, que de início estava ocultada, em razão da estrutura do modelo teórico, porém igualmente presente, como evidenciado na Figura 1 (7.4), demonstrando a negação da indiferença.

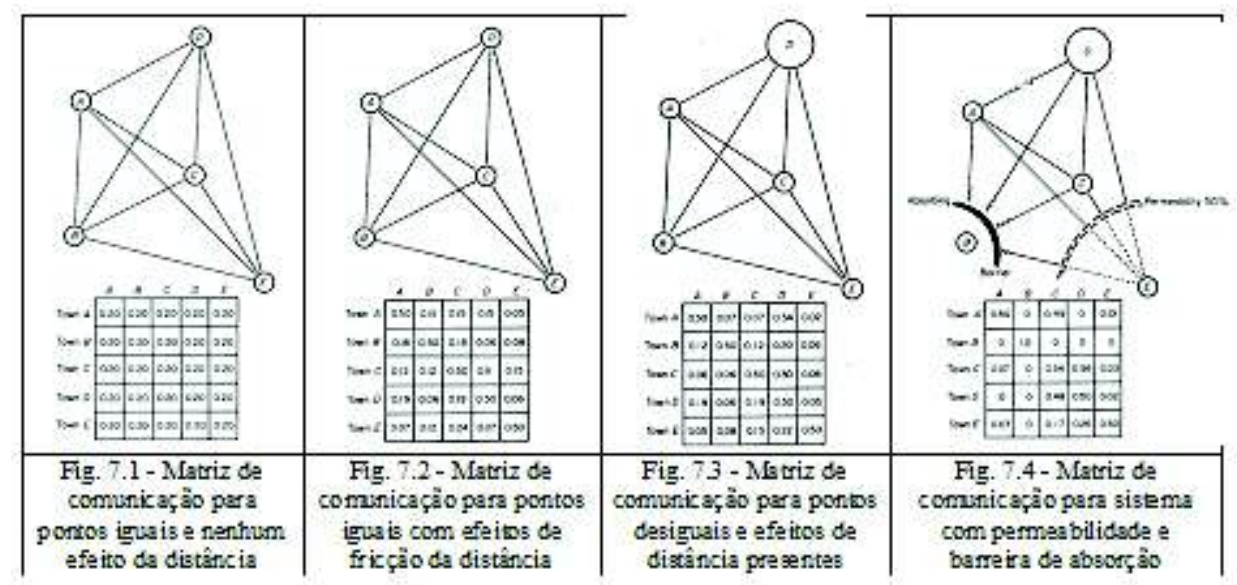

Figura 1 - Exemplo de operacionalização da matriz matemática e da planície isotrópica, as duas principais formas de representação do espaço nas análises da Geografia Teorético-Quantitativa.

Fonte: ABLER, ADANS e GOULD, 1971, p.406-407.

A construção de modelos possibilitou uma aproximação com a economia espacial. Os de von Thünen e Weber inspiraram a produção de uma diversidade de modelos locacionais mais complexos, associados à localização de atividades agrícolas, industriais e comerciais. Taaffe (1975, p.15), a respeito dos modelos de von Thünen e de Weber, assegura que estes “[...] evoluíram para formar séries de modelos locacionais mais complexos, abrangendo uma área mais realística e diversa de comportamento", o que, sem dúvida, possibilita a apreensão da diferenciação espacial. Do mesmo modo, a obra de Christaller (1966), sobre a teoria das localidades centrais, obteve importante reconhecimento e "[...] foi vista como particularmente crítica e foi substituída por uma diversidade de modelos espaciais que lidavam com sistemas de cidades e com modelos dentro de cidades", como 
aponta Taaffe (1975, p.15). Igualmente, o modelo de difusão espacial desenvolvido por Hägerstrand (1967) inspirou a construção de outros mais complexos para a compreensão de uma variedade de processos espaciais. Taaffe $(1975$, p.15) salienta que esse de difusão espacial “[...] passou, rapidamente, de uns poucos e simples postulados envolvendo planícies uniformes e populações homogêneas para modelos complexos que descrevem uma variedade de processos de difusão espacial, cada um com o seu próprio conjunto de efeitos de obstáculo e heterogeneidade socioeconômica", o que evidencia, sem sombra de dúvida, a passagem de uma situação de indiferença para condições de diferenciação espacial . Fica também evidente, contudo, que tais modelos sofreram mutações, pois se tornaram mais complexos, com um elevado grau de abstração, demonstrando a natureza das generalizações. Taaffe (1975, p.17) enfatiza que os modelos desenvolvidos por von Thünen, Lösch, Weber e Christaller "[...] passaram por grandes modificações teoréticas [...] e se tornaram mais explicitamente espaciais".

A perspectiva ou possibilidade de apreensão da diferenciação espacial é evidenciada também nas análises regionais. A região, entretanto, é abordada não como um conceito, mas como um tipo particular de classificação. Gomes (1995, p.64), discutindo a noção de região na corrente lógico-formal, expõe que, nas regras da análise regional, o espaço é dividido segundo critérios ou variáveis de classificação geral, resultando em regiões homogêneas ou isonômicas, cujas divisões "[...] correspondem a verdadeiros níveis hierárquicos e significativos da diferenciação espacial”. As regiões funcionais, por sua vez, “[...] dão forma a um espaço que é internamente diferenciado". Dessa maneira, a diferenciação espacial está presente tanto na concepção de região homogênea como na de região funcional.

Assim, nos modelos espaciais, como expõe Corrêa (1995), determina-se um espaço previamente indiferenciado a partir do qual, em razão de mecanismos econômicos e outras variáveis, dentre as quais a distância, tem-se a possibilidade de leitura da diferenciação espacial. Desta forma, a Geografia Teorético-Quantitativa desenvolveu a temática da diferenciação espacial. Os padrões espaciais resultantes partem, em razão dos pressupostos de racionalidade econômica, de competição perfeita e de a-historicidade, de uma situação de uniformidade espacial, expressa por meio de uma planície isotrópica, que a princípio desconsidera a heterogeneidade, mas, sobre esse espaço isomórfico, desenvolvem-se ações e mecanismos econômicos que levam à diversidade do espaço. Tal procedimento representa uma diferenciação espacial a posteriori, no sentido de ser o espaço um substrato que se diferencia mediante a atuação de um conjunto de variantes econômicas. Contudo a natureza da explicação, nas análises teorético-quantitativistas, permaneceu superficial e simplista, tendo em vista que a própria noção de espaço era restrita e limitada, como observa Corrêa (1995).

A partir das décadas de 1970 e 1980, quando o saber geográfico pela teoria e prática teorético-quantitativista evidenciou esgotamento mediante as severas críticas por parte dos geógrafos radicais, a chamada revolução crítica, de orientação marxista, seguindo uma sequencia de incorporações teórico-metodológicas, introduziu profundas mudanças que alteraram a natureza da Geografia. Corrêa (1995, p.23) assevera que o espaço "[...] reaparece como o conceito-chave, entendido como um produto social", o que significa "[...] partir das estruturas sociais para conhecer a organização do espaço", como salienta Capel (1981, p.436). Mendoza et. al. (1982, p.149-150), a esse respeito, observam que, "[...] no campo específico do conhecimento geográfico, o discurso marxista supõe em todos os casos aceitar a existência de relações mútuas e complexas entre sociedade e espaço, entre processos sociais e configurações espaciais [...]" e, desta forma, "[...] o espaço aparece [...] como um produto social", ou seja, um produto concreto de relações sociais historicamente determinadas.

Uma das contribuições mais importantes para a constituição de uma análise geográfica marxista é feita por Lefèbvre (1976, p.25). O referido autor afirma que o espaço, “[...] desempenha um papel ou uma função decisiva na estruturação de uma totalidade, de uma lógica, de um sistema, e, desta maneira, distingue o espaço como uma dimensão indispensável à construção da realidade social". Essa concepção, para os geógrafos que adotaram a perspectiva marxista, é fundamental, pois dá à realidade social uma dimensão verdadeiramente espacial, de um lado, possibilitando uma análise

Mercator - volume 9, número 20, 2010: set./dez. 
geográfica calcada na dinâmica própria da espacialidade e, de outro lado, garantindo ao espaço um papel-chave na interpretação da sociedade. Neste sentido, Soja (1983) enfatiza que "[...] determinada historicamente, a espacialidade seria, assim, a expressão material das relações sociais", ou seja, a noção de espaço está relacionada com a própria vida material humana, sendo, portanto, dimensão indissociada da sociedade ou, como sugere Haesbaert (2004, p.20), "[...] sociedade e espaço social são dimensões gêmeas". Massey (1981, p.28), por sua vez, ressalta que o espaço é “[...] a esfera de possibilidade da existência da multiplicidade", sendo, portanto, “[...] condição, meio e produto da realização da sociedade em toda a sua multiplicidade", como assegura Carlos (2001, p.11).

Nesse contexto, a diferenciação espacial representa aspecto de primeira ordem, tendo em vista que as pesquisas geográficas orientaram-se, mormente, no sentido de buscar a origem, a natureza e as implicações da diferenciação espacial. Contrariamente à postura da Geografia Teorético-Quantitativa, que tratava a diferenciação espacial com base nas condições homogêneas, evidenciando uma situação de equilíbrio espacial, que cooperava com a manutenção das desigualdades, na perspectiva da Geografia Crítica, a diferenciação espacial é ponto de partida, cujo cerne explicativo repousa no fato de ser o espaço um produto social e, por isto, diferenciado, mesmo num contexto de globalização tendencialmente homogeneizador, porquanto o que se vê é uma permanente reconstrução das diversidades espaciais por meio da recriação das diferenças e de novas desigualdades ou des-igualizações, usando a expressão de Haesbaert (1999).

$\mathrm{Na}$ análise geográfica marxista, duas possibilidades de interpretação da diferenciação espacial são dadas por intermédio dos conceitos de formação socioespacial e de desenvolvimento espacial desigual. Mediante essas derivações, os geógrafos buscaram acrescentar uma dimensão verdadeiramente espacial à análise, até mesmo, com o resgate e a redefinição da noção de região, forma tangível da diferenciação espacial .

\section{A formação socioespacial}

A contribuição de Santos (1977) para a análise geográfica marxista ou, como assevera Peet (1996), para a dialética espacial, aparece com o conceito formação socioespacial, adaptado da categoria formação econômico-social. Tal conceito ou meta-conceito, como observa Corrêa (1995), é crucial para a análise geográfica e, do mesmo modo, para o entendimento dos processos de diferenciação espacial, especialmente em escalas particulares. Esse conceito explicita que uma sociedade só se torna concreta por meio do espaço que ela própria produz e, não obstante, o espaço só se torna inteligível por intermédio dessa sociedade, sendo, portanto, uma instância e um dado constitutivo .

O conceito formação socioespacial orienta-se, primordialmente, no sentido de precisar como um dado modo de produção manifesta-se concretamente nas diversas formações sociais. Para tanto, Santos (1977, p.87) afirma que "[...] os modos de produção tornam-se concretos sobre uma base territorial historicamente determinada [...]" e, nesta perspectiva, "[...] as formas espaciais seriam uma linguagem dos modos de produção", ou melhor, seriam uma linguagem do resultado concreto entre o contato do modo de produção e da formação social preexistente. Santos $(1999$, p.6) ressalta que "[...] modos de produção e espaço geográfico evoluem juntos, movidos pela mesma lógica unitária". Nesse caso, o que se tem é, essencialmente, uma organização espacial do modo de produção, e, desta maneira, pode-se supor que o processo espacial seja uma emanação direta do modo de produção, pois, como esclarece o referido autor, "[...] a cada novo modo de produção (ou a cada novo momento do mesmo modo de produção) mudam a estrutura e o funcionamento do espaço" .

Santos (1977, 1999), entretanto, alerta que a análise do modo de produção, apesar de central, não é suficientemente adequada à compreensão da organização espacial, devendo associar-se ao conceito de formação social. Tal conjunção conceitual permite uma análise reveladora da estrutura e do funcionamento do espaço em suas particularidades, pois “[...] as relações entre espaço e formação social são de outra ordem, pois se fazem num espaço particular e não num espaço geral, tal como para os modos de produção. Os modos de produção escrevem a História no tempo, as formações 
sociais escrevem-na no espaço", como preceitua Santos (1977, p.87-88). De fato, a formação social é uma particularidade espaço-temporal de um determinado modo de produção, quer dizer, é uma combinação particular e relacional de uma ordem temporal e de uma ordem espacial de um dado modo de produção dominante.

Santos (1977, p.86) argumenta que modo de produção, formação social e espaço são categorias interdependentes. Segundo esse autor, "[...] todos os processos que, juntos, formam o modo de produção (produção propriamente dita, circulação, distribuição, consumo) são histórica e espacialmente determinados num movimento de conjunto, e isto através de uma formação social", na qual estão imbricados ou integrados o político, o econômico, o social e o cultural que, em conjunto, correspondem a um todo social. Conforme Santos (1977, p.81), nem o modo de produção e nem a formação social podem ser pensados sem incluir a instância espacial, ou seja, não é possível supor uma formação econômico-social "[...] sem incluir a categoria do espaço" . Para tanto, Santos (1977, p.82) sugere acrescentar ao conceito de formação econômico-social a dimensão espacial. Mais uma vez, nas palavras do autor, "[...] trata-se de fato de uma categoria de Formação Econômica, Social e Espacial" ou, simplesmente, formação espacial. De fato, cada formação econômico-social deve ser vista como uma formação socioespacial, isto é, como uma expressão particular de uma dada articulação dos modos de produção no tempo e no espaço, cuja particularidade é dada pela mediação da formação social.

A mediação das formações sociais impõe um conjunto particular de relações, pois, pela sua própria presença, é capaz de influenciar os momentos subsequentes dos modos de produção. Ambos, modo de produção e formação social, dependem dos atributos ou dos conteúdos do processo espacial, ou melhor, ao mesmo tempo em que o espaço é resultado, é produto, é "[...] matéria moldada pela totalidade da vida social, o espaço também molda as atividades humanas", como assevera Peet (1996, p.165). Nessa perspectiva, não é possível negligenciar a importância da contingência geográfica. A esse respeito, Santos (1977, p.90) observa que

...a unidade da continuidade e da descontinuidade do processo histórico não pode ser realizada senão no espaço e pelo espaço. A evolução da formação social está condicionada pela organização do espaço, isto é, pelos dados que dependem diretamente da formação social atual, mas também das formações econômico-sociais permanentes.

Assim, em tempos de globalização, com um “[...] modo de produção que tende a ser único", o espaço geográfico seria homogeneizado ou uniformizado por intermédio da ação de uma unicidade técnica, que se orienta no plano do universal. Todavia isso não ocorre, pois " [...] a ação deste modo de produção tendencialmente único passa pela mediação das formações espaciais”, que está situada no plano da particularidade. Segundo Santos (1977, p.81), as formações socioespaciais, como etapas de um processo histórico, referem-se à “[...] evolução diferencial das sociedades”, isto é, expressam a diferenciação espacial e, por conseguinte, são dados fundamentais para explicar por que países, regiões, centros urbanos diferenciam-se uns dos outros. Esses participam do processo geral, implementado pelo modo de produção dominante, com graus diferentes de co-presença e de complexidade, pois se definem tanto pela "[...] sua existência corpórea [na esfera da materialidade] quanto por sua existência relacional". Os atributos da universalidade, hoje definida pela globalização, interpenetram-se por meio de uma distribuição não homogênea, incompleta, com os atributos singulares dos lugares. Tal interação dá peculiaridade e distinção, criando particularidades. Como expõe Santos (1999, p.16), “[...] é assim que os subespaços existem e se diferenciam uns dos outros", quer dizer, o fundamento da transformação espacial reside no choque entre o que já existe e o que se impõe como novo, resultando em um espaço diferenciado e também desigual, que aparece como justaposição espaço-temporal, na qual "[...] o espaço, considerado como um mosaico de elementos de diferentes eras, sintetiza, de um lado, a evolução da sociedade e explica, de outro lado, situações que se apresentam na atualidade" (SANTOS, 1985, p.22).

Mercator - volume 9, número 20, 2010: set./dez. 
Em condições histórico-geográficas específicas, a tendência à homogeneização é sempre afetada pela mediação antagônica da formação socioespacial. Essa mediação impõe uma heterogeneidade. Dessa maneira, a universalização dos processos é acompanhada, inversamente, pela singularização e particularização, implicando uma diferenciação.

Para a análise dos processos de diferenciação, a importância do conceito de formação socioespacial reside no fato de tratar-se de uma noção que é indissociável do particular, isto é, a formação socioespacial refere-se a uma sociedade espacial e historicamente determinada e, desta maneira, possibilita o "[...] conhecimento de uma sociedade em sua totalidade e nas suas frações, mas sempre um conhecimento específico, apreendido num dado momento de sua evolução". O fato de o conceito de formação socioespacial ser associado a uma realidade concreta, susceptível, por conseguinte, de localização espaço-temporal, permite o entendimento dos processos de diferenciação espacial, sugerindo inclusive a possibilidade de realização de estudos sincrônicos e diacrônicos.

Santos (1977, p.87) ressalta que “[...] a localização dos homens, das atividades e das coisas no espaço explica-se tanto pelas necessidades 'externas', aquelas do modo de produção 'puro', quanto pelas necessidades 'internas' [...]", estas últimas dadas pela "[...] formação social propriamente dita”. Essa relação dinâmica e, na maioria dos casos, contraditória e conflitante, entre necessidades externas e internas, ou seja, entre as determinações universais do modo de produção, cujos padrões impõem-se de fora para dentro, e as mediações das formações sociais, sob o impulso das elites locais, é dado fundamental para explicar as particularidades dos lugares e, por conseguinte, os processos de diferenciação espacial. Para Santos (1977, p.90), "[...] a assincronia está na base da evolução espacial", resultando em diferenças no espaço, cujas lógicas ocorrem em qualquer escala geográfica, tanto de um país, como de uma região, ou mesmo no que diz respeito aos processos de diferenciação entre cidades, pois é na formação socioespacial que se "[...] entrecuzam determinações gestadas em diversas escalas, do geral e do particular, assim como emergem contingências", como aponta Corrêa (2000, p.124). De fato, a relação dialética entre determinações externas e internas, juntamente com a possibilidade de contingências, revela o movimento da transformação, isto é, da evolução por que passa a estrutura social e a organização espacial, isto é, a formação socioespacial.

\section{O desenvolvimento espacial desigual}

O conceito de desenvolvimento espacial desigual, termo usado por Massey $(1981,1984)$ e que corresponde a desenvolvimento geográfico desigual, empregado por Harvey (2004), a desenvolvimento geograficamente desigual, utilizado por Soja (1983), ou simplesmente a desenvolvimento desigual, usado por Amin (1976), Walker (1978) e Smith (1988), assim como o de formação socioespacial, é essencialmente dialético, visto que foi desenvolvido com base na lei do desenvolvimento desigual e combinado, proposta por Trotsky (1981), e cujas origens podem ser remetidas a Marx (1998) e também a Lênin (1982), que examinou esse conceito quando discutiu o desenvolvimento do capitalismo na Rússia (Novack, Trotsky e Moreno, 1981). Tal lei está diretamente associada a dois processos - desigualdade e combinação, que, apesar de opostos e distintos, possuem racionalidades que coexistem e se relacionam mútua e contraditoriamente, trazendo à tona a possibilidade da interpenetração dos contrários.

A explicação do desenvolvimento desigual é temário de debates entre Sociologia, Antropologia, Economia, Ciência Política e várias outras ciências. Na análise geográfica, o conceito de desenvolvimento espacial desigual é introduzido, como mostra Gomes (1996, p.300-301), num quadro de redefinições do campo de análise marxista, pelo qual se busca “...uma verdadeira dimensão espacial à análise marxista, dimensão frequentemente esquecida em favor de uma explicação histórica ou econômica". Nesse sentido, o conceito de desenvolvimento espacial desigual está relacionado com a noção de espaço como locus da atividade humana, isto é, como uma dimensão real e concreta na qual se dá a materialização das relações de produção e de reprodução da sociedade, quer dizer, onde ocorre a concretização das relações sociais, revelando práticas que são essencialmente espaciais, visto que os diversos conteúdos e materialidades que compõem a existência e a reprodução 
de uma dada sociedade inscrevem-se num dado espaço. Nesse sentido, as relações sociais, em toda a sua multiplicidade, possuem existência real como existência espacial concreta, haja vista que a sociedade, ao produzir sua existência, reproduz, ininterruptamente, o espaço. O espaço, por sua vez, não é simplesmente uma extensão da sociedade, ao contrário, é produto, meio e condição dos múltiplos processos sociais e históricos, resultando, portanto, num espaço diverso e desigual, que, em si mesmo, realimenta os processos de variabilidade espacial.

Assim como a formação econômico-social, a lei do desenvolvimento desigual e combinado também tem uma dimensão espacial. Tal dimensão, como sugerem Massey $(1981,1984)$, Corrêa (1991), Thrift (1996) e outros, traduz-se primordialmente no processo de regionalização, ou seja, a região pode ser pensada como um resultado dessa lei. Dessa maneira, tal lei auxilia na compreensão do desenvolvimento geográfico desigual entre regiões na economia nacional. O termo é também utilizado de forma frequente para explicar o desenvolvimento desigual entre nações na economia internacional; a ampliação desigual entre setores, como, por exemplo, indústria versus agricultura; as transformações desiguais entre economia, cultura e política; e os desdobramentos desiguais da dinâmica das lutas de classes. De modo análogo, pode auxiliar também na explicação das diferenciações entre padrões de crescimento e de declínio de determinados centros urbanos. A despeito desses, é salutar observar que a articulação antagônica entre desigualdade e combinação é fundamentalmente uma questão geográfica, traduzida, sobretudo, no processo de diferenciação espacial. Nessa discussão, Harvey (2004) ressalta a importância premente dos papéis das "[...] transformações geográficas, dos 'ajustes espaciais' e dos desenvolvimentos geográficos desiguais".

A discussão acerca do desenvolvimento, conceito que denota um conjunto de mudanças nas esferas econômicas, políticas, sociais e culturais, e da contradição entre desigualdade e combinação dirige-se para o âmbito universal - contrariamente à da formação socioespacial, cuja lógica associa-se ao particular. A visão de universalidade do desenvolvimento desigual é apontada por Mandel, que explica tratar-se de uma "[...] lei universal da historia humana", não estando, portanto, associada apenas à história do capitalismo. Althusser, nesse mesmo sentido, afirma que o desenvolvimento desigual "...não leva em conta unicamente o imperialismo, mas absolutamente tudo neste mundo". Para esse último autor, o desenvolvimento desigual constitui a essência mais íntima da contradição, isto é, "[...] ele existe na essência da própria contradição" (citado por SMITH, 1988, p.237) . Nessa perspectiva, parece mais adequado, pelo substrato que deriva diretamente da contradição e da própria mudança, utilizar as expressões movimento ou dinâmica, pois se trata de um movimento desigual e combinado, cuja resultante é a diferenciação espacial num sentido amplo.

De fato, tal movimento traduz-se nas tendências opostas para a heterogeneização e a homogeneização, para a diferenciação e a igualização, com base em efeitos divergentes e convergentes, igualmente contraditórios. Trata-se, portanto, de tendências que possuem racionalidades que interagem de forma mútua e contraditoriamente, evidenciando, além da possibilidade da interpenetração dos contrários, dos opostos, a articulação de espaços-tempos distintos e justapostos, que passam a coexistir de modo diverso. Nessa coexistência, ou melhor, na base dessa combinação, residem, paradoxalmente, as raízes da diferenciação, da desigualdade, pois os processos gerais, universalizantes, são sobrepostos e ajustados aos processos antecedentes e à base espacial preexistente. A combinação de sucessivas justaposições produzirá, nas formações socioespaciais, efeitos específicos, que variam no tempo e contribuem para promover e ampliar as diversidades geográficas, pois tais processos materializam-se de maneira distinta e seletiva, assim como sofrem ajustes, em maior ou menor grau, no contato com a própria formação socioespacial, resultando, portanto, numa organização diferenciada do espaço, em contextos multiescalares e pluralizados. Como salienta Massey (1981, p.75), “[...] os efeitos dessa combinação são aqueles que produzem as características específicas das áreas locais e o padrão geral da variação regional numa formação social".

Vale ressaltar que as análises geográficas sobre o desenvolvimento espacial desigual são realizadas de forma contemporânea e tratam, especificamente, das contradições do capitalismo. Todavia Soja $(1983$, p.55) assevera que o desenvolvimento espacial desigual descreve a padronização geral

Mercator - volume 9, número 20, 2010: set./dez. 
da espacialidade dos modos de produção, sendo, desta maneira, "[...] uma característica inerente da expressão material das relações de produção e da divisão do trabalho, através da qual a própria espacialidade é definida", isto é, a produção espacial desigual é resultante de condições e situações sociais e histórico-geográficas específicas e, neste aspecto, a combinação espaço-sociedade traz implícita uma desigualdade que se materializa por meio da diferenciação espacial.

Para muitos autores, a força transformadora principal que modela o mundo é o capitalismo e suas contradições. Smith (1988, p.16-17) observa que uma teoria do desenvolvimento espacial desigual "[...] oferece a chave para determinar o que caracteriza a geografia específica do capitalismo". De modo semelhante, Soja (1983, p.34/35) reconhece a existência de uma "[...] espacialidade diferenciada e desigualmente desenvolvida... [como expressão] ....aplicada a um capitalismo intrinsecamente desequilibrado". Não obstante, Massey (1981) advoga que o processo de acumulação capitalista gera o desenvolvimento desigual do espaço e, por isto, representa ferramenta importante para a compreensão desse mesmo processo. Nesse mesmo sentido, Harvey (1982, p.415-416) argumenta que "[...] o capitalismo não se desenvolveu sobre uma planície plana dotada de matérias-primas ubíquas, com oferta homogênea de trabalho e com iguais facilidades de transportes em todas as direções", ao contrário, “[...] está inserido, cresce e se difunde no interior de um variado ambiente geográfico que engendra uma grande diversidade na generosidade da natureza e na produtividade do trabalho". Assim, tal associação revela o desenvolvimento espacial desigual como expressão geográfica do capitalismo, na tendência contraditória entre a desigualdade e a combinação, entre heterogeneidade e homogeneidade, entre convergência e divergência, pois, como ensina Harvey (1982, p.417), "[...] o desenvolvimento desigual está parcialmente expresso em uma oposição entre duas forças que se objetam, moldada para a concentração ou para a dispersão na circulação do capital".

\section{DIFERENCIAÇÃO ESPACIAL E A CORRELAÇÃO ENTRE LÓGICAS SINGULARES, PARTICULARES E UNIVERSAIS}

A análise dos conceitos tem capacidade reveladora. A correlação entre racionalidades universais, particulares e singulares produz diferencialidades socioespaciais. Por isso, a análise da diferenciação espacial perpassa pelo reconhecimento da relação dialética e, portanto, com características opostas entre tais racionalidades, particularmente na interconexão entre as escalas do universal-singular e do universal-particular , pois as diferenciações espaciais são fruto das imbricações complexas entre essas dimensões. Imbricações fundamentadas, de um lado, numa universalização incompleta, uma vez que a mudança não ocorre em bloco, pelo contrário, ela própria é seletiva, desigual e esbarra em ações e materialidades resistentes; de outro, nas forças que recusam, em menor ou maior grau, essa universalização; e, por fim, na assincronia entre processos convergentes e divergentes, cujas lógicas conformam assentimentos, recusas e deformações. Imperando os efeitos convergentes, nos quais as mudanças ocorrem por meio de continuidades, os contextos acatam mais prontamente as racionalidades hegemônicas, sendo, consequentemente, remodelados; imperando os efeitos divergentes, nos quais as mudanças acontecem por meio de descontinuidades, os contextos recusam expressivamente tais racionalidades; e numa situação relativa de coexistência, as racionalidades hegemônicas podem ser exercidas sobre um dos elementos constitutivos e esbarrar nas resistências de outros, criando deformações. Trata-se de uma dialética caracterizada por continuidades, descontinuidades e rupturas, posto que o contato entre lógicas universais e lógicas singulares, por vezes convergentes, por vezes divergentes, ou pela co-presença de ambos os processos, produz particularidades, cujas combinações são igualmente únicas.

Trata-se de uma questão complexa, que envolve a dinâmica relacional entre processos opostos e antagônicos, cuja causa e resultante inerente é a contradição, visto que os embates ocorrem entre equalização e diferenciação, homogeneização e heterogeneização, universalização-singularização, global e local, convergência e divergência. Os processos, as funções e as formas dos já diferenciados fragmentos de espaço redefinem-se a cada momento, por meio de uma complexa relação dialética 
entre essas lógicas singulares, particulares e universais, entre os fatores internos e externos, entre o choque do novo e do velho, que desequilibram as estruturas preexistentes. A articulação entre eles é dado fundamental para a explicação, uma vez que a ação universal, que se implanta de forma seletiva e desigual, transforma e é também transformada por ações condicionantes, criando mediações particulares , que também complexificam sua relação com o processo geral. São dimensões que se interpenetram, produzindo diversidades e heterogeneidades, assim como desigualdades. Cumpre ressaltar que o singular vincula-se aos processos de heterogeneização/diferenciação e materializa-se como o oposto dialético do universal, com suas tendências homogeneizadoras/igualizantes.

Esses processos possuem uma dimensão espacial premente. Em realidade, suas possibilidades são efetivamente possibilidades próprias à expansão geográfica. Nessa perspectiva, o espaço geográfico é redefinido e reestruturado em dimensões e escalas diversas e múltiplas. Nas palavras de Harvey (2004, p.110), “[...] o exame do mundo em qualquer escala particular revela de imediato toda uma série de efeitos e processos que produzem diferenças geográficas nos modos de vida, nos padrões de vida, nos usos de recursos, nas relações com o ambiente e nas formas políticas e culturais". Tais efeitos e processos vinculam-se às assimetrias entre os fatores convergentes e divergentes em distintas escalas , resultando em diferenciação espacial. Contudo "[...] trabalhar simultaneamente com diferenciações geográficas voláteis e em multiplicação que operam em planos escalares, eles mesmo em rápida mudança", torna-se uma tarefa difícil, como observa Harvey (2004, p.114).

Nessas circunstâncias, a cada momento histórico, que inclui novas formas de produção e acumulação, novas relações político-econômicas e novas estruturas socioculturais, tem-se o embate entre a continuidade, a descontinuidade e a ruptura dos processos, caracterizando a incessante renovação da sociedade e, por conseguinte, a recriação constante de diferenciações espaciais. Nas palavras de Harvey (2004, p.12/111),

...o mosaico geográfico sempre esteve em movimento em toda e qualquer escala... ainda que as variações geográficas reflitam e incorporem legados materiais, históricos, culturais e políticos do passado... [posto que] ....as diferenciações geográficas são bem mais que legados histórico-geográficos. Elas estão sendo perpetuamente reproduzidas, sustentadas, solapadas e reconfiguradas por meio de processos políticoseconômicos e socioecológicos que ocorrem no momento presente.

Os imperativos universais são continuamente determinados pela imposição de novas racionalidades, que oferecem um cenário propício às estratégias e às ações hegemônicas, isto é, são coerentes com o funcionamento de uma ordem global. Todavia a singularidade do arranjo local age de modo a resistir às mudanças, seja pelas formas e funções preexistentes, seja pelas intencionalidades locais, que mantêm suas coerências singulares, pois, como os lugares têm seus valores, significados, as heterogeneidades dos lugares impõem-se a cada novo momento, ou melhor, contrapõem-se aos planos universalizantes. Como enfatiza Santos (citado por Silveira, 1999, p.447), "[...] o lugar permite a possibilidade de construir uma história das ações que seja diferente do projeto dos atores hegemônicos".

Ambas, lógicas universais e singulares, passam a refletir combinações particulares que, ao se concretizarem, o fazem de modo distinto, criando e sustentando as diversidades. É assim que as forças universais se defrontam com as resistências da formação socioespacial. Essa é a dialética em questão, que se constrói por meio do confronto e da síntese entre essas racionalidades, nas quais a ação universalizante passa pela inconteste mediação das formações socioespaciais. Como salienta Santos (1999, p.6), “[...] a mediação do Estado, da sociedade civil e da própria configuração territorial herdada são dados fundamentais para explicar as diferenças [...]”. Essa dinâmica de produção da diferença geográfica, contudo, é desigual. A difusão seletiva dos imperativos universais é incompleta e se dá desigualmente, segundo os países, as regiões, os centros urbanos, contribuindo para ampliar as diferenças, cuja existência complexa já se faz presente pela mediação da formação socioespacial. A consequência é a ampliação da diversidade espacial, orientada pela coexistência

Mercator - volume 9, número 20, 2010: set./dez. 
entre racionalidades universais e singulares, como uma manifestação do movimento desigual e combinado.

A escolha racional e seletiva dos lugares por parte dos agentes hegemônicos agrava as desigualdades, pois, como aponta Santos $(1999$, p.9), "[...] os atores hegemônicos da vida econômica, política e social podem escolher os melhores lugares para sua atuação e, em consequência, a localização dos demais atores é condenada a ser residual". O resultado é a coexistência desses processos, inerentes ao dinamismo da sociedade e fortemente associados ao movimento desigual e combinado, expresso tanto na diferenciação propriamente dita como na desigualdade.

Nota-se, entretanto, que a diferenciação do espaço geográfico não é somente uma forma de desigualdade e, sim, uma questão de diferença. Dessa maneira, o problema desloca-se notadamente para o conceito de diferença, discutido, mesmo que de forma implícita, na Geografia por meio dos conceitos de diferenciação de área, região, formação socioespacial, território, lugar, dentre outros, visto que a diferenciação espacial é dado essencial à natureza da Geografia.

\section{CONSIDERAÇÕES FINAIS}

A construção das necessárias mediações entre a realidade e as reflexões teóricas impõe-se à Geografia como condição para o entendimento do espaço geográfico. Tal construção deve estar fundamentada em preocupações com os conteúdos desse espaço, dentre os quais se ressalta, neste texto, o da diferenciação espacial.

A diferenciação espacial representa importante viés de apreciação por parte dos geógrafos, pois é materialidade particular, singular, uma vez que é visível no plano do imediato e do diretamente perceptível, sendo resultado da complexa relação dialética entre as lógicas singulares, particulares e universais, entre os fatores internos e externos, entre o choque do novo e do velho, que envolve a dinâmica relacional entre processos opostos e antagônicos, cuja causa e resultante inerente é a contradição, visto que os embates ocorrem também entre equalização e diferenciação, homogeneização e heterogeneização, global e local, convergência e divergência, continuidade e descontinuidade, a partir dos quais a indiferenciação do espaço não passa de um mito; e, no plano intelectual, é possibilidade analítica, que instrumenta e fertiliza a explicação geográfica, que é aquela que se orienta na direção do desvendamento dos processos constitutivos do espaço.

De fato, na sua aplicação na Geografia, a noção de diferenciação espacial possui, de um lado, uma reflexividade prático-empírica, já que os conteúdos da diferença na paisagem, na região, no espaço, no território, no lugar são absolutamente tangíveis; e, de outro lado, tem uma reflexividade teórica e metodológica, que amplia as possibilidades de problematização da realidade socioespacial É por isso que se impõe a necessidade de refletir o problema de ser a diferenciação espacial essencial à natureza da Geografia. No entanto, esta síntese apresenta-se como uma pequena e inacabada contribuição.

\section{REFERÊNCIA BIBIOGRÁFICA}

ABLER, Ronald; ADANS, John S.; GOULD, Peter. Spatial organization: the geographer's view of the world. New Jersey: Prentice-Hall. 1971. 587p.

AMIN, Samir. O desenvolvimento desigual: ensaio sobre as formações sociais do capitalismo. Rio de Janeiro: Forense-Universitaria, 1976. 334p.

BESSA, Kelly C. F. O. Convergências e divergências da urbanização em áreas de cerrado: a dinâmica urbano-regional de Uberaba e Uberlândia (MG). 2007. 371f. Tese (Doutorado em Geografia) - Programa de Pós-Graduação em Geografia da Universidade Federal do Rio de Janeiro, Rio de Janeiro. 2007.

CAPEL, Horacio S. Filosofía y ciencia en la geografía contemporánea. Barcelona: Editorial Barcanova, 1981.509 p.

CARLOS, Ana Fani A. Espaço-tempo na metrópole: a fragmentação da vida cotidiana. São Paulo: Contexto, 2001.368p. 
CHRISTALLER, Walter. Central places in Southern Germany. Prentice-Hall/Englewood Cliffs, 1966. 230p. CORRÊA, Roberto L. Rede urbana e formação espacial - uma reflexão considerando o Brasil. Território, Rio de Janeiro: Garamond, ano V, n.8, p.121-129, jan./jun.2000.

CORREAA, Roberto L. Espaço, um conceito-chave da Geografia. In: CASTRO, Iná E. de; GOMES, Paulo Cesar da C.; CORRÊA, Roberto L. (Org.). Geografia: conceitos e temas. Rio de Janeiro: Bertrand Brasil, 1995. p.15-47.

CORREAA, Roberto L. Região e organização espacial. São Paulo: Ática, 1991. 93p.

CORRÊA, Roberto L. O estudo da rede urbana: uma proposição metodológica. Revista Brasileira de Geografia, Rio de Janeiro, ano 50, n.2, p.107-124, abr./jun.1988.

DHOQUOIS, Guy. La formación económico-social como combinación de modos de produción. In: CUADERNOS DE PASADO Y PRESENTE n.39. El concepto de "formación económico-social". México: Ediciones Pasado y Presente/Siglo XXI Editores, 1973. p.185-195.

GOMES, Paulo César da C. Geografia e modernidade. Rio de Janeiro: Bertrand Brasil, 1996. 366p.

GOMES, Paulo César da C. O conceito de região e sua discussão. In: CASTRO, Iná E. de; GOMES, Paulo Cesar da C.; CORREAA, Roberto L. (Org.). Geografia: conceitos e temas. Rio de Janeiro: Bertrand Brasil, 1995. p.49-76.

GREGORY, Derek. Teoria social e geografia humana. In: GREGORY, Derek; MARTIN, Ron; SMITH, Grahan. (Org.). Geografia humana: sociedade, espaço e ciência social. Rio de Janeiro: Jorge Zahar, 1996. p.90-122. GREGORY, Derek. Areal differentiation and post-modern human geography. In: GREGORY, Derek; WALFORD, Rex. Horizons in human geography. London: Macmillan Education, 1989. p.67-96.

HAESBAERT, Rogério. O mito da desterritorialização: do "fim dos territórios" à multiterritorialidade. Rio de Janeiro: Bertrand Brasil, 2004. 395p.

HAESBAERT, Rogério. Morte e vida da região: antigos paradigmas e novas perspectivas da Geografia Regional. In: ENCONTRO ESTADUAL DE GEOGRAFIA, XXII, 2003, Porto Alegre. Anais... Porto Alegre: AGB-Porto Alegre/Fundação Universidade de Rio Grande/Fapergs, 2003. 19-38.

HAESBAERT, Rogério. Região, diversidade territorial e globalização. Geographia, Niterói, ano 1, n.1, p.15-39, jun.1999.

HÄGERSTRAND, Torsten. Innovation diffusion as a spatial process. Chicago: The University of Chicago Press, 1967. 334p.

HARTSHORNE, Richard. The nature of geography. Annals of the Association of American Geographers, Washington, n.XXIX, p.173-658, 1939.

HARVEY, David. Espaços de esperança. São Paulo: Edições Loyola, 2004. 382p.

HARVEY, David. The limits to capital. Chicago: Basil Blackwell Publisher, 1982. 478p.

HARVEY, David. Explanation in geography. Londres: Edward Arnold, 1969. 521p.

HOBSBAWN, Eric. Formações econômicas pré-capitalistas. Rio de Janeiro: Paz e Terra, 1977.

LACOSTE, Yves. Unité et diversité du tiers monde. Paris: François Maspero, 1980. 203p. (v.3).

LEFÈBVRE, Henri. Espacio y política: el derecho a la ciudad. Barcelona: Ediciones Península, 1976. 157p.

LÊNIN, Vladimir I. O desenvolvimento do capitalismo na Rússia: o processo de formação do mercado interno para a grande indústria. São Paulo: Abril Cultural, 1982. 402p.

LUKÁCS, George. Introdução a uma estética marxista: sobre a categoria da particularidade. Rio de Janeiro: Civilização Brasileira, 1978. 298p.

LUPORINI, Cesare. Dialética marxista e historicismo. In: CUADERNOS DE PASADO Y PRESENTE n.39. El concepto de "formación económico-social". México: Ediciones Pasado y Presente/Siglo XXI Editores, 1973. p.162-166.

MARX, Karl. O capital. Rio de Janeiro: Civilização Brasileira, 1998.

MARX, Karl; ENGELS, Friedrich. A ideologia alemã. 9 ed. São Paulo: Hucitec, 1993. 138p.

MASSEY, Dorreen. Spatial divisions of labour: social structures and the geography of production. London: Macmillian Publishers, 1984. 339p.

Mercator - volume 9, número 20, 2010: set./dez. 
MASSEY, Dorreen. Regionalismo: alguns problemas atuais. Espaço e Debates, São Paulo, ano 1, n.4, p.50-83, dez.1981.

MENDOZA, Josefina G.; JIMÉNEZ, Julio M.; CANTERO, Nicolás O. El pensamiento geográfico: estudio interpretativo y antología de textos (de Humboldt a las tendencias radicales). Madrid: Alianza Editorial, 1982. 545p.

MOREIRA, Ruy. A diferença e a Geografia. Geographia, Niterói, ano 1, n.1, p.41-58, jun.1999.

NOVACK, George; TROTSKY, León; MORENO, Nahuel. La ley del desarrollo desigual y combinado. Cidade do México: Ediciones Quinto Sol, 1981.122p.

PEET, Richard. Milton Santos no exílio: os anos de setenta. In: SOUZA, Maria Adélia A. (Org.). O mundo do cidadão: um cidadão do mundo. São Paulo: Hucutec, 1996. p.164-168.

SANTOS, Milton. Modo de produção técnico-científico e diferenciação espacial. Território, Rio de Janeiro, n.6, p.5-20, jan./jun. 1999.

SANTOS, Milton. Espaço e método. São Paulo: Nobel, 1985. 88p.

SANTOS, Milton. O trabalho do geógrafo no terceiro mundo. São Paulo: Hucitec, 1978. 113p.

SANTOS, Milton. Sociedade e espaço: a formação social como teoria e como método. Boletim Paulista de Geografia, São Paulo: AGB, n.54, p.81-99, jun.1977.

SERENI, Emílio. La categoria de "formación económico-social". In: CUADERNOS DE PASADO Y PRESENTE n.39. El concepto de "formación económico-social”. México: Ediciones Pasado y Presente/ Siglo XXI Editores, 1973. p.55-95.

SILVEIRA, Maria L.. Um país, uma região: fim de século e modernidades na Argentina. São Paulo: Fapesp/ Laboplan-USP, 1999. 488p.

SMITH, Neil. Desenvolvimento desigual: natureza, capital e a produção de espaço. Rio de Janeiro: Bertrand Brasil, 1988. 250p. [Uneven development, 1984].

SOJA, Edward W. Uma concepção materialista da espacialidade. In: BECKER, Bertha K.; COSTA, Rogério H.; SILVEIRA, Carmen B. (Org.). Abordagens políticas da espacialidade. Rio de Janeiro: UFRJ/Departamento de Geografia/Programa de Pós-Graduação em Geografia, 1983. p.22-74.

TAAFFE, Edward J. A visão espacial em conjunto. Boletim Geográfico, Rio de Janeiro, ano 34, n.247, p.5-27, out./dez. 1975.

TEXIER, Jacques. Desabcuerdos sobre la definición de los conceptos. In: CUADERNOS DE PASADO Y PRESENTE n.39. El concepto de "formación económico-social". México: Ediciones Pasado y Presente/ Siglo XXI Editores, 1973. p.190-195.

THRIFT, Nigel. Visando o âmago da região. In: GREGORY, Derek; MARTIN, Ron; SMITH, Grahan. (Org.). Geografia humana: sociedade, espaço e ciência social. Rio de Janeiro: Jorge Zahar, 1996. p.215-247.

TROTSKY, León. Particularidades en el desarrollo de Rusia. In: NOVACK, George; TROTSKY, León; MORENO, Nahuel (Org.). La ley del desarrollo desigual y combinado. Cidade do México: Ediciones Quinto Sol, 1981.p.79-103.

URRY, John. Social relations, space end time. In: GREGORY, Derek; URRY, John. Social relations and spatial structures. London: Macmillan, 1985. p.20-48.

WALKER, Richard A. Two sources of uneven development under advanced capitalism: spatial differentiation and capital mobility. The Review of Radical Political Economics, New York, v.10, n.3, p.28-36, 1978.

WATSON, J. W. Geography - a discipline in distance. Scottish Geographical Magazine. Edinhurgh, v.7, n.1, p.1-13, 1955.

Trabalho enviado em setembro de 2010

Trabalho aceito em dezembro de 2010 